\title{
Associations between temporary employment and occupational injury: what are the mechanisms?
}

\author{
F G Benavides, J Benach, C Muntaner, G L Delclos, N Catot, M Amable

See end of article for authors' affiliations

.....................

Correspondence to: Dr F G Benavides, Occupational Health Research Unit, Pompeu Fabra University, Carrer Doctor Aiguader 80 08003 Barcelona, Spain fernando.benavides@ upf.edu

Accepted

10 February 2005

Published Online First

23 February 2006
Objective: To determine whether observed higher risks of occupational injury among temporary workers are due to exposure to hazardous working conditions and/or to lack of job experience level.

Methods: Data systematically recorded for 2000 and 2001 by the Spanish Ministry of Labour and Social Affairs on fatal and non-fatal traumatic occupational injuries were examined by type of employment and type of accident, while adjusting for gender, age, occupation, and length of employment in the company. In the study period there were 1500 fatal and 1806532 non-fatal traumatic occupational injuries that occurred at the workplace. Incidence rates and rate ratios (RR) were estimated using Poisson regression models.

Results: Temporary workers showed a rate ratio of 2.94 for non-fatal occupational injuries $(95 \% \mathrm{Cl} 2.40$ to 3.61 ) and 2.54 for fatal occupational injuries $(95 \% \mathrm{Cl} 1.88$ to 3.42$)$. When these associations were adjusted by gender, age, occupation, and especially length of employment, they loose statistic significance: 1.05 (95\% Cl 0.97 to 1.12) for non-fatal and 1.07 (95\% Cl 0.91 to 1.26$)$ for fatal.

Conclusions: Lower job experience and knowledge of workplace hazards, measured by length of employment, is a possible mechanism to explain the consistent association between temporary workers and occupational injury. The role of working conditions associated with temporary jobs should be assessed more specifically.

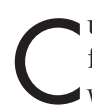
urrent global economic trends have increased new forms of flexible employment (for example, temporary work, contingent, part-time contract, unregulated work, home based work, and other non-traditional work arrangements). Most flexible jobs are defined as precarious. Precarious employment is a complex labour market situation with several characteristics: temporary work status, job vulnerability, low social protection (for example, unemployment and sickness absence benefits) and low income level. ${ }^{12}$ Temporary employment may be considered a practical indicator of this construct, because it is usually recorded in labour statistics. ${ }^{3}$

Evidence in this area has advanced quickly, and some adverse health consequences of new forms of flexible employment have been reported. ${ }^{4}$ For example, job insecurity over time has been associated with poor mental health, ${ }^{5}$ whereas job insecurity due to downsizing has been associated with sickness absence. ${ }^{6}$ Temporary employment has been related with job dissatisfaction, and with a higher prevalence of fatigue, backache, and muscular pains than permanent employment. ${ }^{7}$ More recently, one study reported that temporary workers have a higher mortality rate than permanent workers, particularly for alcohol and smoking related causes of death. ${ }^{8}$

There are several reasons why Spain has an important role in the study of health effects of flexible employment. In the European Union (EU-15) as a whole, ${ }^{9}$ the number of temporary workers in 2002 was 13.2 million, or $11.9 \%$ of the total employed labour force. Spain had the highest percentage of temporary workers $(31.2 \%)$ in the EU-15. In fact, even among Spanish workers age 40 years and over, temporary employment still reaches $17 \%$. On the other hand, occupational injuries are still a high priority on the occupational health agenda. ${ }^{10}$ Spain also has one of the highest incidence rates of fatal and non-fatal occupational injuries in the EU-15. ${ }^{11}$

There have been some studies addressing the relation between temporary employment and occupational injuries. A recent revision has reported that seven of 13 relevant studies show a consistent increased risk of occupational injuries among temporary workers. ${ }^{12}$ In that revision, it is suggested that the association among temporary workers may be related to their greater inexperience and lack of safety training at the workplace, although the association may be biased by confounding related to occupation. In Spain a descriptive study found that temporary workers had a twofold or greater risk of occupational injury than permanent workers. ${ }^{13}$ This difference in risk has been observed in Spain since the beginning of the last decade. ${ }^{14}$

Therefore, the next question is to explore the mechanisms that could explain these differences. The hypothesis considered in this paper is that the higher risk of occupational injury among temporary workers is due to two mechanisms acting simultaneously: temporary workers are exposed to more hazardous working conditions and to less job experience than permanent workers.

We tested this hypothesis by comparing fatal and non-fatal traumatic occupational injury rates between temporary and permanent workers in Spain, taking into account occupational category (as an indicator of working conditions) and length of employment (as an indicator of worker experience).

\section{SUBJECTS AND METHODS}

\section{Occupational injury data}

Occupational injuries among salaried workers have been systematically recorded in Spain since 1989 by the Ministry of Labour and Social Affairs in accordance with compulsory rules. ${ }^{15}$ In order for workers to receive medical care and social protection, an official work accident form must be completed by a physician from an insurance company for any occupational injury resulting in the loss of at least one working day for a non-fatal occupational injury. The Spanish labour statistics administration endorses the Eurostat ${ }^{11}$ definition of fatal occupational injury: "an injury which causes the death of the victim during the year following the date of the injury". The quality of these occupational injury statistics in 
terms of sensitivity, predictability, and representativeness has previously been found to be adequate. ${ }^{16}{ }^{17}$ The reporting of fatal occupational injuries is estimated to be $99 \% .{ }^{18}$

The present study was based on the complete data files on all occupational injuries occurring at the workplace (excluding relapses, commuting accidents, and non-traumatic injuries) from the two most recently available years-2000 and 2001. Incident traumatic occupational injuries at work were selected for study because their work relatedness is more straightforward. The sample size was 1808032 (1500 fatal) occupational injuries: 898955 (773 fatal) in 2000 and 909077 (727 fatal) in 2001.

Type of employment at the time of the injury is recorded on the occupational injury form, and is classified as either permanent (unlimited permanent contract) or temporary (employed on a fixed term contract, temporary employment agency contract, apprenticeship, or other training scheme, etc) by the National Institute of Statistics according to type of contract. For each occupational injury the following information was used: gender and age (six groups) as demographic variables, occupation (nine categories) as an indicator of working conditions, and length of employment in the company (three categories) as an indicator of worker experience in the specific workplace. Occupation titles were classified according to the International Standard Occupational Classification ${ }^{19}$ in nine categories. In the last category (non-qualified and elementary occupations) are included cleaners, janitors, shop assistants, bricklayers, miners, etc. The length of employment categories were selected according to percentile distribution for both temporary and permanent workers $(\mathrm{P} 25=2.4$ months, $\mathrm{P} 50=9.6$ months, and P75 $=45.6$ months $)$.

Occupational injuries were classified according to the type of accident, given that some notified occupational injuries could be not work related, as they could happen during leisure time. For this study, based on expert opinions from a previous study, ${ }^{14}$ they were divided into two groups: occupational injuries clearly related to work (fall from a height, being hit by falling objects, falling object being manipulated, projectile fragments or particles, trapped by or between objects, trapped by vehicles or machinery rollover, exposure to extreme temperatures, thermal contact, contact with electrical current, exposure to harmful substances, exposure to caustics or corrosive substances, exposure to ionising radiation, explosions, and fires) and occupational injuries possibly related to work (fall on the same level, stepped on object, struck against stationary object, struck by a moving object, struck by an object or tool, overexertion, and pedestrian run over or struck by vehicle). During the study period, in the first group there were 511924 , and in the second group, there were 1296108 events.

\section{At risk population data}

The National Institute of Statistics labour force survey data on salaried workers for 2000 and 2001 were used as the best available denominator in the analysis. ${ }^{20}$ Although the true population at risk is composed of workers registered under the national social security insurance system, this database is not accessible and does not contain information on worker occupations. The labour force survey has been found to provide a good denominator estimate, except for the agriculture and fishing economic sectors. ${ }^{21}$ A large proportion of workers in these two latter sectors are under a special social security system for self-employed workers, which is not as well accounted for as salaried workers in the labour force survey.

\section{Statistical analysis}

Incidence rates were estimated for fatal and non-fatal occupational injuries. In order to improve accuracy, mainly for fatal occupational injury rates, both years were analysed jointly, after observing that there were no meaningful differences between the two years. Poisson regression models were used to estimate the rate ratio (RR) and 95\% confidence intervals $(95 \% \mathrm{CI})$, using permanent workers as the reference group. In addition to the calculation of crude estimates, the ratios were also adjusted for gender, age (categorical), occupation, and length of employment in the company. Adjustment by occupation and length of employment was done to assess their mediating role, since these two variables, according the study hypothesis, were considered as explanatory variables rather than confounding factors. A stratified analysis of the two groups by type of accident was carried out.

The likelihood ratio test, based on the Fisher-Snedecor distribution, was used to assess the goodness-of-fit of models, as well as a marginal approach to correct Poisson overdispersion (standard errors scaled using square root of deviance based dispersion).22 SPSS statistical software was used for processing data file, and STATA for all analyses. All p values were two-sided, with values less than 0.05 indicating statistical significance.

\section{RESULTS}

Compared with permanent workers, temporary workers showed significantly higher RR of traumatic occupational injuries (tables 1 and 2), almost threefold greater for nonfatal ( $R R=2.94 ; 95 \%$ CI 1.88 to 3.42 ) and two and half times greater for fatal occupational injuries ( $\mathrm{RR}=2.54 ; 95 \% \mathrm{CI} 1.88$ to 3.42 ). This was particularly apparent in men, and for older age groups.

The highest non-fatal occupational injury incidence rates, for either permanent or temporary employment, were observed among workers with less than six months of employment in the company $\left(156.3 / 10^{3}\right.$ and $185.4 / 10^{3}$, respectively), and the lowest rates were for those with more than 24 months' tenure in companies $\left(35.4 / 10^{3}\right.$ and $67.2 / 10^{3}$, respectively). However, among workers with more than 24 months of employment in a company, temporary workers had higher incidence rates compared with permanent workers $(\mathrm{RR}=1.90 ; 95 \%$ CI 1.20 to 3.03$)$. A similar pattern was observed for fatal occupational injuries.

For all occupational categories, temporary workers showed significantly higher risks than permanent workers for nonfatal occupational injuries. In the case of fatal occupational injuries, significant associations were only found for manual categories: craft and related trades workers, plant and mechanic operators, and non-qualified and elementary occupations. For service workers and skilled agricultural and fishery workers the risk of fatal injuries was highest, but not significant among permanent workers.

These crude relative risks showed a remarkable decrease in magnitude after adjusting by occupation, and particularly by length of employment (table 3), and were no longer significant after adjusting by gender, age, occupation, and length of employment. However, when the analysis was repeated by type of accident (table 4 ), a significant association emerged for fatal injury clearly related to work $(\mathrm{RR}=1.30 ; 95 \%$ CI 1.08 to 1.57$)$.

\section{DISCUSSION}

Results from this study show that the risk of occupational injury is unequally distributed between temporary and permanent employment: temporary workers have higher risk than permanent workers. However, after adjusting by occupation, and particularly length of employment, the risk of occupational injury among temporary workers approximates that of permanent workers. These findings provide 
Table 1 Incidence and rate ratio (RR) of non-fatal occupational injuries in temporary and permanent workers by gender, age, length of employment, and occupation; Spain 2000-01.

\begin{tabular}{|c|c|c|c|c|c|c|c|c|c|}
\hline & \multicolumn{6}{|c|}{ Non-fatal } & \multirow[b]{3}{*}{ RR } & \multirow[b]{3}{*}{$95 \% \mathrm{Cl}$} & \multirow[b]{3}{*}{$\mathrm{p}$ Value } \\
\hline & \multicolumn{3}{|c|}{ Permanent } & \multicolumn{3}{|l|}{ Temporary } & & & \\
\hline & Injury & $\begin{array}{l}\text { Population } \\
\text { at risk }\end{array}$ & Incidence* & Injury & $\begin{array}{l}\text { Population } \\
\text { at risk }\end{array}$ & Incidence* & & & \\
\hline \multicolumn{10}{|l|}{ Gender } \\
\hline Male & 617146 & 10711368 & 57.6 & 867285 & 4676785 & 185.4 & 3.22 & $2.52-4.09$ & 0.000 \\
\hline Female & 141706 & 6285581 & 22.5 & 180680 & 3289099 & 54.9 & 2.44 & $1.85-3.21$ & 0.000 \\
\hline \multicolumn{10}{|l|}{ Age group (years) } \\
\hline$<20$ & 10127 & 103053 & 98.3 & 82454 & 551285 & 149.6 & 1.52 & $0.93-2.49$ & 0.092 \\
\hline $20-24$ & 72855 & 991021 & 73.5 & 240876 & 1753346 & 137.4 & 1.87 & $1.21-2.89$ & 0.005 \\
\hline $25-34$ & 229166 & 5100155 & 44.9 & 355930 & 3091752 & 115.1 & 2.56 & $1.69-3.87$ & 0.000 \\
\hline $35-44$ & 210398 & 5214363 & 40.3 & 212869 & 1560713 & 136.4 & 3.38 & $2.32-4.92$ & 0.000 \\
\hline $45-54$ & 153887 & 3805100 & 40.4 & 114885 & 749844 & 153.2 & 3.79 & $2.69-5.32$ & 0.000 \\
\hline$>54$ & 82419 & 1783257 & 46.2 & 40951 & 258944 & 158.1 & 3.42 & $2.37-4.94$ & 0.000 \\
\hline \multicolumn{10}{|l|}{ Length of employment in company +} \\
\hline$<6$ months & 80758 & 516638 & 156.3 & 660009 & 3560499 & 185.4 & 1.19 & $0.74-1.87$ & 0.482 \\
\hline 6-24 months & 160689 & 1867164 & 86.1 & 290600 & 2955725 & 98.3 & 1.14 & $0.82-1.60$ & 0.419 \\
\hline$>24$ months & 517398 & 14613147 & 35.4 & 97353 & 1449660 & 67.2 & 1.90 & $1.20-3.03$ & 0.006 \\
\hline \multicolumn{10}{|l|}{ Occupations (ISCO-88)‡ } \\
\hline Legislators, senior officials and managers & 2764 & 468775 & 5.9 & 598 & 34817 & 17.2 & 2.91 & $1.72-4.81$ & 0.000 \\
\hline Professionals & 12340 & 2470441 & 5.0 & 7360 & 707093 & 10.4 & 2.08 & $1.46-2.98$ & 0.000 \\
\hline Technicians and associate professionals & 23206 & 2158923 & 10.7 & 13210 & 554688 & 23.8 & 2.22 & $1.60-3.06$ & 0.000 \\
\hline Clerks & 27773 & 2250525 & 12.3 & 20638 & 671213 & 30.7 & 2.49 & $1.63-3.80$ & 0.000 \\
\hline Service workers and shop and market sales & 115429 & 2604908 & 44.3 & 105683 & 1242312 & 85.1 & & & \\
\hline workers & & & & & & & 1.92 & $1.32-2.79$ & 0.001 \\
\hline Skilled agricultural and fishery workers & 12933 & 204822 & 63.1 & 14939 & 123981 & 120.5 & 1.91 & $1.34-2.72$ & 0.000 \\
\hline Craft and related trades workers & 275976 & 2636609 & 104.7 & 398894 & 1713002 & 232.9 & 2.22 & $1.62-3.05$ & 0.000 \\
\hline Plant and machine operators and assemblers & 134928 & 2000849 & 67.4 & 101570 & 788387 & 128.8 & 1.91 & $1.34-2.73$ & 0.000 \\
\hline Non-qualified and elementary occupations & 153393 & 2077399 & 73.8 & 384933 & 2081132 & 185.0 & 2.50 & $1.54-4.08$ & 0.000 \\
\hline Total & 758852 & 16996949 & 44.6 & 1047965 & 7965884 & 131.6 & 2.94 & $2.40-3.61$ & 0.000 \\
\hline $\begin{array}{l}\text { *Incidence per } 1000 \text { workers. } \\
\text { †Ten missing values. } \\
\text { †Excluded "Armed Forces". }\end{array}$ & & & & & & & & & \\
\hline
\end{tabular}

Table 2 Incidence and rate ratio (RR) of fatal occupational injuries in temporary and permanent workers by gender, age, length of employment, and occupation; Spain 2000-01

\begin{tabular}{|c|c|c|c|c|c|c|c|c|c|}
\hline & \multicolumn{6}{|l|}{ Fatal } & \multirow[b]{3}{*}{$\mathbf{R} \mathbf{R}$} & \multirow[b]{3}{*}{$95 \% \mathrm{Cl}$} & \multirow[b]{3}{*}{ p Value } \\
\hline & \multicolumn{3}{|c|}{ Permanent } & \multicolumn{3}{|c|}{ Temporary } & & & \\
\hline & Injury & $\begin{array}{l}\text { Population } \\
\text { at risk }\end{array}$ & Incidence* ${ }^{*}$ & Injury & $\begin{array}{l}\text { Population } \\
\text { at risk }\end{array}$ & Incidence* & & & \\
\hline \multicolumn{10}{|l|}{ Gender } \\
\hline Male & 667 & 10711368 & 6.2 & 799 & 4676785 & 17.1 & 2.74 & $2.01-3.73$ & 0.000 \\
\hline Female & 18 & 6285581 & 0.3 & 16 & 3289099 & 0.5 & 1.70 & $0.92-3.13$ & 0.088 \\
\hline \multicolumn{10}{|l|}{ Age group (years) } \\
\hline$<20$ & 3 & 103053 & 2.9 & 22 & 551285 & 4.0 & 1.37 & $0.52-3.66$ & 0.538 \\
\hline $20-24$ & 21 & 991021 & 2.1 & 87 & 1753346 & 5.0 & 2.34 & $1.11-4.91$ & 0.025 \\
\hline $25-34$ & 141 & 5100155 & 2.8 & 241 & 3091752 & 7.8 & 2.82 & $1.61-4.96$ & 0.000 \\
\hline $35-44$ & 214 & 5214363 & 4.1 & 236 & 1560713 & 15.1 & 3.68 & $2.17-6.26$ & 0.000 \\
\hline $45-54$ & 177 & 3805100 & 4.7 & 161 & 749844 & 21.5 & 4.62 & $2.74-7.79$ & 0.000 \\
\hline$>54$ & 129 & 1783257 & 7.2 & 68 & 258944 & 26.3 & 3.63 & $2.07-6.38$ & 0.000 \\
\hline \multicolumn{10}{|l|}{ Length of employment in companyt } \\
\hline$<6$ months & 73 & 516638 & 14.1 & 521 & 3560499 & 14.6 & 1.04 & $0.47-2.26$ & 0.940 \\
\hline 6-24 months & 138 & 1867164 & 7.4 & 221 & 2955725 & 7.5 & 1.01 & $0.61-1.69$ & 0.952 \\
\hline$>24$ months & 474 & 14613147 & 3.2 & 73 & 1449660 & 5.0 & 1.55 & $0.78-3.11$ & 0.205 \\
\hline \multicolumn{10}{|l|}{ Occupations (ISCO-88)† } \\
\hline Legislators, senior officials and managers & 14 & 468775 & 3.0 & 0 & 34817 & 0.0 & 0.00 & - & - \\
\hline Professionals & 20 & 2470441 & 0.8 & 7 & 707093 & 1.0 & 1.22 & $0.48-3.13$ & 0.675 \\
\hline Technicians and associate professionals & 56 & 2158923 & 2.6 & 26 & 554688 & 4.7 & 1.81 & $0.78-4.19$ & 0.168 \\
\hline Clerks & 16 & 2250525 & 0.7 & 7 & 671213 & 1.0 & 1.47 & $0.51-4.22$ & 0.477 \\
\hline Service workers and shop and market sales workers & 37 & 2604908 & 1.4 & 14 & 1242312 & 1.1 & 0.79 & $0.26-2.42$ & 0.685 \\
\hline Skilled agricultural and fishery workers & 53 & 204822 & 25.9 & 14 & 123981 & 11.3 & 0.44 & $0.17-1.11$ & 0.082 \\
\hline Craft and related trades workers & 194 & 2636609 & 7.4 & 269 & 1713002 & 15.7 & 2.13 & $1.31-3.49$ & 0.002 \\
\hline Plant and machine operators and assemblers & 230 & 2000849 & 11.5 & 252 & 788387 & 32.0 & 2.78 & $1.42-5.43$ & 0.003 \\
\hline Non-qualified and elementary occupations & 65 & 2077399 & 3.1 & 226 & 2081132 & 10.9 & 3.47 & $1.38-8.73$ & 0.008 \\
\hline Total & 685 & 16996949 & 4.0 & 815 & 7965884 & 10.2 & 2.54 & $1.88-3.42$ & 0.000 \\
\hline
\end{tabular}


Table 3 Type of employment and occupational injuries (referent category: permanent workers). Rate ratio (RR) and 95\% confidence interval (95\% Cl) adjusted by gender, age (categorical), occupation, and length of employment; Spain 2000-01

\begin{tabular}{|c|c|c|c|c|c|c|}
\hline & \multicolumn{3}{|c|}{ Non-fatal } & \multicolumn{3}{|l|}{ Fatal } \\
\hline & $\mathbf{R R}$ & $95 \% \mathrm{Cl}$ & p Value & $\mathbf{R R}(*)$ & $95 \% \mathrm{Cl}(*)$ & p Value \\
\hline $\begin{array}{l}\text { Crude } \\
\text { Adjusted individually by: }\end{array}$ & 2.94 & $2.40-3.61$ & 0.000 & 2.54 & $1.88-3.42$ & 0.000 \\
\hline Gender & 3.06 & $2.56-3.65$ & 0.000 & 2.71 & $2.16-3.39$ & 0.000 \\
\hline Age & 2.95 & $2.37-3.66$ & 0.000 & 3.40 & $2.52-4.59$ & 0.000 \\
\hline Occupation & 2.21 & $1.94-2.50$ & 0.000 & 2.22 & $1.76-2.81$ & 0.000 \\
\hline Length of employment & 1.35 & $1.04-1.74$ & 0.023 & 1.15 & $0.77-1.72$ & 0.490 \\
\hline $\begin{array}{l}\text { Adjusted jointly by gender, age, } \\
\text { occupation, and length of } \\
\text { employment }\end{array}$ & 1.04 & $0.97-1.12$ & 0.276 & 1.07 & $0.91-1.26$ & 0.402 \\
\hline
\end{tabular}

some evidence about the link between type of employment and the risk of occupational injury.

Our results confirm earlier studies that found an excess risk of occupational injury among temporary workers, ${ }^{12}$ and provides new insight into the mechanism underlying the association. These findings need to be replicated before they are taken as causal evidence. The study of this association in other countries, especially those with a lower proportion of temporary workers, would seem to be a logical next step since there is no guarantee that temporary employment has the same meaning and health effect impact in different countries.

Despite occupational injury statistics being considered complete in Spain, ${ }^{16}{ }^{18}$ the accuracy of specific items such as type of employment or length of employment is unknown, and it is possible that temporary workers might be more likely to have inaccurate data than permanent workers. Furthermore, temporary workers may be underreporting occupational injuries because of fears of being stigmatised or fired, ${ }^{23}$ which would lead to an underestimate of the strength of the association. Primary data collection is needed to improve the measurement of temporary employment and confirm our findings. Indeed, given that temporary workers are likely to have fewer work hours actually worked, the true risk may actually be understated by the population denominator used in this study.

Conversely, the cross sectional design of the study could lead to an overestimation of the strength of reported association, because an inverse relation could be possible: workers with a high frequency of occupational injuries could lose opportunities to become permanent in their jobs. This hypothesis should be tested in a longitudinal framework study, although it is likely that this selection bias influence would be small.

According to our hypothesis, the association between temporary employment and occupational injuries can be explained by two mechanisms. Firstly, temporary workers are exposed to more hazardous working conditions than permanent workers. As observed from the distribution of workers by occupation: $26.1 \%$ of temporary workers versus $12.2 \%$ of permanent workers had non-qualified and elementary occupations, and $16.3 \%$ versus $30 \%$, respectively, had management, professional, or technical occupations. In fact, the Third European Survey on Working Conditions has shown that workers with non-permanent contracts are more likely to have unfavourable working conditions such as repetitive movements, painful and tiring positions, discrimination, low time control, and/or less freedom to choose when

Table 4 Type of employment and occupational injuries by type of accident: clearly and possibly work related (referent category: permanent workers). Rate ratio (RR) and 95\% confidence interval $(95 \% \mathrm{Cl})$ adjusted by gender, age (categorical), occupation, and length of employment; Spain 2000-01.

\begin{tabular}{|c|c|c|c|c|c|c|}
\hline & \multicolumn{3}{|c|}{ Clearly work related } & \multicolumn{3}{|c|}{ Possibly work related } \\
\hline & RR & $95 \% \mathrm{Cl}$ & $p$ Value & RR & $95 \% \mathrm{Cl}$ & p Value \\
\hline \multicolumn{7}{|l|}{ Non-fatal } \\
\hline Crude & 3.13 & $2.50-3.91$ & 0.000 & 2.87 & $2.36-3.51$ & 0.000 \\
\hline \multicolumn{7}{|l|}{ Adjusted individually by: } \\
\hline Gender & 3.27 & $2.72-3.93$ & 0.000 & 2.98 & $2.50-3.55$ & 0.000 \\
\hline Age & 3.14 & $2.48-3.97$ & 0.000 & 2.88 & $2.33-3.55$ & 0.000 \\
\hline Occupation & 2.32 & $2.02-2.67$ & 0.000 & 2.16 & $1.91-2.44$ & 0.000 \\
\hline Length of employment & 1.39 & $1.05-1.84$ & 0.022 & 1.33 & $1.04-1.71$ & 0.024 \\
\hline $\begin{array}{l}\text { Adjusted jointly by gender, } \\
\text { age, occupation, and } \\
\text { length of employment }\end{array}$ & 1.05 & $0.98-1.13$ & 0.184 & 1.04 & $0.96-1.12$ & 0.327 \\
\hline \multicolumn{7}{|l|}{ Fatal } \\
\hline Crude & 3.14 & $2.28-4.32$ & 0.000 & 1.95 & $1.40-2.72$ & 0.000 \\
\hline \multicolumn{7}{|l|}{ Adjusted individually by: } \\
\hline Gender & 3.36 & $2.64-4.28$ & 0.000 & 2.08 & $1.58-2.73$ & 0.000 \\
\hline Age & 4.42 & $3.23-6.04$ & 0.000 & 2.45 & $1.74-3.46$ & 0.000 \\
\hline Occupation & 2.38 & $1.86-3.04$ & 0.000 & 2.04 & $1.58-2.62$ & 0.000 \\
\hline Length of employment & 1.60 & $1.04-2.47$ & 0.034 & 0.77 & $0.50-1.18$ & 0.229 \\
\hline $\begin{array}{l}\text { Adjusted jointly by gender, } \\
\text { age, occupation, and }\end{array}$ & 1.30 & $1.08-1.57$ & 0.006 & 0.84 & $0.69-1.04$ & 0.110 \\
\hline length of employment & & & & & & \\
\hline
\end{tabular}


to take personal leave. ${ }^{24}$ Spanish surveys on working conditions show a similar pattern, especially in relation to ergonomic and psychosocial risk factors..$^{25}$ In conclusion, on the whole, temporary workers toil in occupations with more hazardous working conditions. However, within occupational groups, temporary workers show significantly higher risks than permanent workers in almost all occupations, especially for non-fatal injuries. An explanation for this remarkable finding could be that temporary workers have less experience and knowledge of the workplace than permanent workers. In fact, when the length of employment is taken into account the observed association disappears in each group (data not shown), except for skilled agricultural and fishery workers. An alternative explanation could be that there were only nine occupational categories, and within each category there are different types of jobs. This may have led to underadjustment of the role of occupationally linked working conditions in the study. However, the persistent effect of temporary work in relatively homogeneous strata of occupations suggests that the first explanation has substantial merit. The role of working conditions in the observed association should be further assessed with more detailed information on work organisation and workplace hazards.

An unexpected inverse association was observed between permanent services workers, and skilled agricultural and fishery workers and fatal occupational injuries. A plausible explanation could be that many temporary workers in these occupations are self-employed, and do not record suffering occupational injuries. ${ }^{21}$

A second mechanism should be considered as a possible explanation for these findings: permanent workers are likely to have better knowledge and experience of the workplace, tools, and activities than temporary workers. The results show, on the one hand, a clear inverse trend between length of employment and occupational injury risk, among both permanent and temporary workers: risk decreases when length of employment increases. However on the other hand, the RR was only statistically significant for permanent workers. These patterns did not change significantly after taking into account occupation. Both results are not paradoxical. Less than six months is the most hazardous employment situation in any case, and experience within the workplace protects against occupational injury risk, but this protection is less in the case of a worker with a temporal contract of less than 24 months of duration.

Conversely, despite older workers having more experience and compensating ability (safer work behaviours), ${ }^{26}$ aging seemed to increase the risk of occupational injuries, especially fatal occupational injuries, among temporary workers. This could be partly due to the cumulative effect of hazardous exposures among temporary workers, to a lesser capacity of adaptation to changes in working conditions, and also to their age related weakness and vulnerability when facing occupational exposures.

This significant role played by the length of employment has to be considered with caution, because given the cross sectional design of the study and the time related nature of the length of employment, it is likely that some potential bias could affect the results. For instance, workers with less than six months of employment, where the risk of occupational injury was highest, have less probability of being included in a cross sectional study than workers with more than 24 months. However, this bias, if present, could underestimate the magnitude of the association.

Finally, a significant association persisted for fatal injuries clearly related to work after adjusting by occupation and length of employment. Other mechanisms could explain this excess risk among temporary workers. A new hypothesis is that temporary workers are exposed to more stressful

\section{Main messages}

- Findings confirm that temporary workers have a significantly higher risk of having fatal and non-fatal occupational injuries than permanent workers.

- Lower job experience of temporary workers may partially explain why they are at a higher risk of experiencing occupational injuries.

- The role of working conditions should be specifically investigated regarding the association between temporary employment and occupational injuries.

\section{Policy implications}

- Promoting a higher level of permanent employment, with all of its benefits, is an important way towards preventing occupational injuries.

- Increasing workers' knowledge of workplace hazards, especially among temporary workers, is an additional way of reducing the risk of occupational injuries.

circumstances due to greater job vulnerability than permanent workers. Recently, it has been observed that the relation between psychosocial risk factors and sickness absence was stronger among non-permanent workers than permanent workers. ${ }^{27}$ This association has been explained in terms of an increase in effort and productivity. It could, therefore, be suggested that temporary workers have a greater risk of occupational injury because they work at a more accelerated pace. The need to save time and tighter schedules, which significantly affect subcontractors, have been identified as risk factors in a series of 99 serious occupational injuries. ${ }^{28}$

The association found in this study, attributed to the multiple vulnerabilities associated with temporary employment, should be assessed more specifically and in greater detail. Other mechanisms related to precarious employment such as the structural characteristics of the workplace (lack of unionisation or social benefits), or discrimination by both supervisors and permanent workers, should also be taken into account in further analyses. ${ }^{12}$

In conclusion, promoting a higher level of permanent employment, with all of its attendant benefits, is clearly one way to prevent the risk of occupational injury, especially in Spain where the level of temporary employment is extremely high. However, increasing workers' knowledge of their workplace, especially among temporary workers, could be an additional way to reduce the risk of occupational injury.

\section{ACKNOWLEDGEMENTS}

Project support was provided by a grant from the Ministry of Science and Technology (BSA2001-0965) and the Carlos III Health Institute (RCESP C03/09).

\section{Authors' affiliations}

F G Benavides, J Benach, N Catot, M Amable, Occupational Health Research Unit, Department of Experimental and Health Sciences, Pompeu Fabra University, Barcelona, Spain

C Muntaner, Institute for Work and Health, Toronto, Canada

G L Delclos, Southwest Center for Occupational and Environmental Health, The University of Texas School of Public Health, Houston, TX, USA

Competing interests: none. 


\section{REFERENCES}

1 Amable M, Benach J, González S. La precariedad laboral y su repercusión sobre la salud: concepto y resultados preliminares de un estudio multimétodos. Arch Prev Riesgos Labor 2001;4:169-84.

2 Benach J, Benavides FG, Platt S, et al. The health-damaging potential of new types of flexible employment: a challenge for public health researchers. Am J Public Health 2000;90:1316-17.

3 Benach J, Amable M, Muntaner C, et al. The consequences of flexible work for health: are we looking in the right place? J Epidemiol Comm Health 2002;56:405-6.

4 Bartley M. Job insecurity and its effect on health. J Epidemiol Comm Health 2005:718-19.

5 Ferrie JE, Shipley MJ, Marmot MG, et al. Health effects of anticipation of job change and non-employment: longitudinal data from the Whitehall II study. BM 1995;331:1264-9.

6 Kivimäki M, Vahtera J, Penti J, et al. Factors underlying the effect of organisational downsizing on health of employees: longitudinal cohort study. BMJ 2000;320:971-5.

7 Benavides FG, Benach J, Diez-Roux AV, et al. How do types of employment relate to health indicators? Findings from the second European survey on working conditions. J Epidemiol Community Health 2000;54:494-501.

8 Kivimäki M, Vahtera J, Virtanen $M$, et al. Temporary employment and risk of overall and cause-specific mortality. Am J Epidemiol 2003;158:663-8.

9 Eurostat. Labour force survey. Results 2000. Luxembourg: Office for official publications of the European Communities, 2003.

10 Benach J, Muntaner C, Benavides FG, et al. A new occupational health agenda for a new work environment. Scand J Work Environ Health 2002;28:191-6.

11 Eurostat. European social statistics. Accidents at work and work-related health problems. Data 1994-2000. Luxembourg: European Commission, 2003

12 Virtanen $M$, Kivimäki $M$, Virtanen $P$, et al. Temporary employment and health: a review. Int J Epidemiol 2005;34:610-22.

13 Boix $\mathbf{P}$, Orts E, López MJ, et al. Modalidades de contratación y siniestralidad laboral en España en el periodo 1988-1995. MAPFRE Seguridad 1998;69:15-27.

14 Durán F, Castellanos F, Benavides FG, et al. Informe sobre los riesgos laborales y su prevención. Madrid: Presidencia del Gobierno, 2001.
15 Ministerio de Trabajo y Asunto Sociales. Estadísticas de Accidentes de Trabajo. Available at http://www.mtas.es/estadisticas/Inicioa01.htm (accessed May 2005)

16 Benavides FG, Serra C. Evaluación de la calidad del sistema de información sobre lesiones por accidentes de trabajo en España. Arch Prev Riesgos Labor 2003;6:26-30.

17 Klaucke DN. Evaluating public health surveillance systems. In: Halperin W Baker E, eds. Public health surveillance. New York: Van Nostrand Renhold, 1992:26-41.

18 Benavides FG, Pérez G, Martínez JM, et al. Underreporting of fatal occupational injuries in Catalonia (Spain). Occup Med (Oxford) 2004:54:110-14.

19 Mannetie $A^{\prime} t$, Kromhout $\mathrm{H}$. The use of occupation and industry classification in general population studies. Int J Epidemiol 2003;32:419-28.

20 Instituto Nacional de Estadística. Encuesta de Población Activa. Available at http://www.ine.es/inebase/cgi/um?M=\%2Ft22\%2Fe308\&O= inebase\&N $=\& \mathrm{~L}$ (accessed May 2005).

21 Benavides FG, Catot N, Giráldez MT, Castejón E, Delclós J. Comparación de la incidencia de lesiones por accidente de trabajo según la Encuesta de Población Activa y el Registro de Afiliados a la Seguridad Social. Arch Prev Riesgos Labor 2004;7:16-21.

22 McCullagh P, Nelder JA. Generalized linear models (2nd edition). London: Chapman and Hall, 1990.

23 Guadalupe M. The hidden costs of fixed term contracts: the impact on work accidents. London: London School of Economics and Political Science, 2002.

24 Letournoux V. Precarious employment and working conditions in the European union, European Foundation for the improvement of living and working conditions. Luxembourg: Office for Official Publications of the European Communities, 1998.

25 Instituto Nacional de Seguridad e Higiene en el Trabajo. IV Encuesta Nacional de Condiciones de Trabajo. Madrid: INSHT, 2001

26 Laflamme L, Menckel E. Aging and occupational accidents. A review of the literature of the three decades. Safety Science 1995;21:145-61.

27 Gimeno D, Benavides FG, Amick III BC, et al. Psychosocial factors and workrelated sikness absence among permanent and non-permanent employees. J Epidemiol Comm Health 2004;58:870-6.

28 Salminen S, Saari J, Saarela KL, et al. Organizational factors influencing serious occupational accidents. Scan J Work Environ Health 1993;19:352-7. 